\section{Youth suicide trends in the Republic of Ireland}

\author{
MICHAEL J. KELLEHER
}

The Republic of Ireland, with a population of 3525719 , is 94\% Roman Catholic (Central Statistics Office, 1991). Traditionally, it has had a very low rate of suicide, but this has been rising over the past 20 years (Daly \& Kelleher, 1987; Walsh et al, 1990). This rise can be partly explained by the improvement in the method of collecting statistics. In fact, over the past 20 years the ratio of suicide to undetermined death has increased 10 fold: from $\mathbf{2 . 2}$ to $\mathbf{2 8 . 6}$ for males and from 2.3 to 26.9 for females. However, the rise is genuine. It has been estimated that the improved gathering of statistical information accounts for no more than $40 \%$ of the rise in male suicides since the late 1980s (Kelleher et al, 1996).

This rise in Irish suicide rates differs markedly by gender and these differences are increasing with time. There has been a slight rise in the 20- to 24-year-old female suicide rate but, overall, the female suicide rate in Ireland has been stable for the past 20 years. The main rise is in males, in the 20- to 24-year-old age group. There is a significant but less dramatic rise in the 15 to 19-year-old age group. For 15- to 24year-olds, the ratio of male suicide to female suicide in Ireland is 7.1:1 for the years 1988-1992. This represents the highest ratio of all countries that returned suicide statistics to the World Health Organization over this five-year period (World Health Organization Health Statistics Annuals, 1989-1995). Of the 10 countries with the highest male : female suicide ratios in this time period, seven were English-speaking and were, at one stage, part of the British Empire. If the differences are not artefactual, this would suggest that some shared cultural heritage is influencing suicidal behaviour in their young people.

When the male suicide rate in Ireland is looked at for each one-year age group it is seen that there is a stepwise increase in the frequency of suicide. This is in keeping with findings elsewhere (Shaffer et al, 1988) and would fit with a biological model incorporating the increased prevalence of mood disorder and, perhaps, the use of illicit drugs. While the presence of mood disorder might explain the rising frequency of suicide in each one-year age group, it cannot explain the overall increase in suicide between the present and 20 years ago, unless one assumes that mood disorder has also increased in prevalence in the past 20 years.

However, there is no compelling evidence that mood disorder is more common today than it was two decades ago (Casey, 1997). Rather, it appears that a depressed young man today will more readily consider and act upon thoughts of suicide than he would have done a generation ago. The reason for this change could possibly be cultural and relate to the transformation of societies throughout the world, but particularly in the Western world, towards postmodernity and, more specifically, individualisation.

In this context, Ireland has experienced considerable social and cultural change over the past two or three decades. The public practice of religious worship is a salient example. National surveys have shown that the number of people attending Mass, receiving Communion and confessing their sins to a priest has greatly diminished (McGréil, 1991). As well as this, religious and doctrinal belief has waned, for example, in such concepts as hell, infallibility of the Pope and the Bible as the word of God. At the ecological level, there would appear to be an inverse relationship between the rise in suicide and the decrease in religion, but an exploration of the relationship reveals some discrepancies. The greatest rise in young peoples' suicide has occurred in rural areas, yet these are the areas that have remained most loyal to Church practices. The smallest rise has occurred in urban areas and in the east of the country where Dublin is situated (Kelleher et al, 1998). It is these areas that have experienced the greatest reduction in the outward practice of religion. Therefore, these religious factors do not provide a full explanation of the rise in suicide among the young in Ireland.

A second major change in Irish society over the past 20 years, and in particular, over the past decade, has been the increasing availability of illegal drugs. Drugrelated factors are thought to be important in suicide in late adolescence (Hawton et al, 1993) and have been suggested as a major cause of the rise of suicide in the young (Neeleman \& Farrell, 1997). This would not appear to be a significant cause of the rise in Irish suicide rates because there are more cases of drug misuse referred in the Eastern Health Board (EHB) with a population of 1.2 million than in all of the rest of the country (2.4 million) and yet the EHB has the lowest suicide rate (Kelleher et al, 1998). However, it may be that the health services available in the $\mathrm{EHB}$ area are adequate to deal with the problem, whereas in other areas services may be insufficient even to deal with the cases of drug misuse that do occur.

Another major social change in Ireland relates to the proportion of young people continuing their education beyond the minimum school-leaving age of 15 years. Forty-six per cent of 15- to 24-year-olds were still in school in 1991, compared with $28 \%$ in 1971 . The number of tertiary level places has increased from 31000 to 103000 in 20 years. In particular, the gender ratio of students has changed quite dramatically; $62 \%$ were male in the academic year 1975/1976 and this has fallen steadily, with 1995/1996 being the first year in the history of the state when the majority of tertiary level students were female. Access to tertiary level education is dependent on the number of points achieved in the Leaving Certificate examination. The entry requirements for courses have increased every year, making competition for places very intense. Although it is well recognised that the system is stressful to students, teachers and parents, it is so far unclear whether or not it has contributed to the rise in young suicides in Ireland.

Investigating this problem, recent research into the association between suicide and education in Ireland has found that the incidence of suicides among students of leaving certificate age is not associated with the time of the sitting or the release of results of state examinations. When student, 
employed and unemployed 15- to 24-yearold males were examined over an 18-year period (1976-1993), it was found that students actually had the lowest rate of suicide and the unemployed had the highest rate (data available from the author upon request).

Along with changes in levels of drug misuse, religious practise and the education system, the institution of the family in Ireland has undergone considerable transformation. Although divorce was legalised only in 1996 the number of legal separations has been increasing over the years. Marriage rates have fallen steadily and the average age at marriage has increased. At the same time, the majority of parents are under 25 years of age and on average $25 \%$ of children are born outside of marriage in some urban areas the proportion is even higher than this. Such social changes may alter how children and adolescents perceive themselves.

If the changes in the nuclear family are important in disposing towards a rise in suicide, then an explanation must be offered as to why it is that young males have shown the rise and not young females. The overall trend seems to be towards the exclusion of males from the family unit. If there is a separation, it is usually the male parental figure that leaves the home. Therefore, male role models for

MICHAEL J. KELLEHER, FRCPsych, National Suicide Research Foundation, I Perrott Avenue, College Road Cork, Republic of Ireland. Tel: 353-21-277499; Fax: 353-21-277545; e-mail: nsrf@iol.ie

(First received 15 June 1998, final revision 17 June 1998, accepted 30 June 1998)

adolescents may be perceived in a less permanent and more negative way today than they were 20 years ago.

There are many other changes in Irish society in recent years that have not yet been the subject of analysis. These include increasing urbanisation, marked internal migration and widespread industrialisation as well as a great increase in the gross national product. Economically, the country is more competitive both internally and with its European neighbours. Any of these factors could contribute to the increase in suicide. It should be emphasised, however, that the rise in young male suicide simply reflects what is happening in many Western societies and it is unwise to seek a purely internal system of causation rather than a wider one shared with many other countries.

\section{REFERENCES}

Casey, P. (1997) The psychiatric and social background to suicide - the problem of prevention. Irish Medical journal, 90, 12.
Central Statistics OMice (1991) Census Report. Volume I. Dublin: Government Stationery Office.

Dahy, M. \& Kelleher, M. J. (1987) The increase in the suicide rate in Ireland. Irish Medical Journal, 80. 233-234.

Hawton, K., Fage, J., Platt, S., et el (1993) Factors associated with suicide after parasuicide in young people. British Medical journal, 306, 1641-1644.

Kelleher, M. J., Corcoran, P., Koeley, H. S., et al (1996) Improving procedures for recording suicide statistics. Irish Medical journal, 89, 16-17.

- . - (1990) Variation in suicide rates between Health Board areas. Irish Medical Journal, 91, 53-56.

McGréll, M. (1991) Religious Proctice and Attitude in Irelond. Maynooth: St Patrick's College Survey and Research Unit.

Noeleman, J. \& Farrell, M. (1997) Suicide and substance misuse. British journal of Psychiatry. 171 . 303-304.

Shaffer, D., Gartand, A., Could, M., et al (I9es) Preventing teenage suicide: A critical review. Journol of the American Academy of Child and Adolescent Psychiatry, 27, 675-687.

Walsh, D. Cullen, A., Cullivan, R., ot ol (1990) Do statistics lie: suicide in Kildare and Ireland. Psychological Medicine, 20, 867-87I.

World Hadth Organization (19e9-1995) World Health Statistics Annuals. Geneva: WHO. 